\title{
CORRESPONDENCE
}

\section{SPECIALIST TRAINING IN CHILD PSYCHIATRY} DeAr Sir,

I read with much interest the article in the July 1978 Bulletin ( $p$ 127) entitled 'The Role, Responsibilities and Work of the Child and Adolescent Psychiatrist'. I was very concerned to read under heading No. 1 that 'specialist training in Child Psychiatry starts at Senior Registrar level'. This is particularly worrying for me as my position is as a non-rotating registrar in Child Psychiatry in this department. I rotated to this department during my General Psychiatry training for six months in 1976 and then returned in April 1977 to take up a Registrar post in Child Psychiatry. I regarded this as starting my specialist training in Child Psychiatry and continued in this post until the present time. I will find it very difficult if people do not regard this as specialist training in Child Psychiatry when I subsequently apply for other posts, and I wonder on what basis it is said that specialist training in Child Psychiatry only starts at Senior Registrar level.

An additional comment on the article is my regret that the position in Scotland is not elaborated in more detail, the only reference being that the 'situation may be different in Scotland'.

Royal Hospital for Sick Children,

Simon Wilkinson

\section{Rillbank Terrace,}

Edinburgh EH9 ILL

DeAr Sir,

Thank you for offering the opportunity to comment on the letter from Dr Simon Wilkinson.

His six months in 1976 spent as Registrar in the Department of Child Psychiatry would be regarded as a desirable part of his general professional training in preparation for the M.R.C.Psych. examination. The view of our Section is that all trainees in General Psychiatry should have some exposure to Child Psychiatry at Registrar level, as part of their training to become general psychiatrists. He, therefore, would have more than fulfilled this requirement.

There are a few Registrar posts in Child Psychiatry throughout the United Kingdom. However, our Section discourages the establishment of further Child Psychiatric training posts at Registrar level on the following grounds. The Child Psychiatry Section considers that the general training to become a psychiatrist should take place at S.H.O. and Registrar level. This would culminate in the trainee obtaining the M.R.C.Psych. diploma. He will then be qualified to start advanced specialist training in Adult Psychiatry or one of the sub-specialties of Psychiatryand this will properly take place at Senior Registrar level. Experience has taught many Consultant Child Psychiatrists that if they accept a psychiatrist into a Registrar post in Child Psychiatry before the trainee has obtained the M.R.C.Psych., difficulties occur in helping the trainee to pass the examination.

I am, however, quite confident that any Advisory Appointments Committee would accept Dr Wilkinson's length of experience in Child Psychiatry-at both Registrar and Senior Registrar level-as being the determining fact in deciding whether or not he had satisfied the criteria for a particular Consultant post.

The Executive Committee of our Section accepts the criticism that the document was biased towards the practice of Child Psychiatry in England and Wales. In many respects the structure of the Child Psychiatry services in the NHS is different in Scotland and the Working Party did not include a Scottish representative. One example of the differences in Scotland is that it is now most unusual for teaching hospitals to have Registrars in Child Psychiatry on their establishment.

\section{Chairman Child and Adolescent Psychiatry Section}

Bristol Children's Hospital,

St. Michael's Hill,

Bristol BS2 8BJ

\section{IMPRISONMENT OF MENTALLY DISORDERED OFFENDERS}

Dear SiR,

I read with interest Dr J. H. Orr's article (British Journal of Psychiatry, September 1978, 133, 194-9).

During the course of the past few years, I have been asked to provide a psychiatric opinion on a number of people appearing before the local Courts. Some of these individuals have been on remand in prison for long periods of time and often had a number of previous psychiatric reports from all over the country.

On reading through some of these reports, one is made aware of an extremely worrying aspect of present assessment. In many cases the body of the report was devoted to an accurate description of the symptoms, which in ordinary clinical practice would lead to a diagnosis of schizophrenia. However, when it came to discussing the management of the person, the suggestions made appeared to owe more to expediency than to clinical judgement. The mental gymnastics employed in order to match suggested management to the diagnosis were of Olympic standards. It is frighteningly evident that decisions are being influenced by pressures applied by outside agencies rather than being made on the psychiatrist's 